\title{
Integration in the European higher education area: the case of military education
}

\section{Francisco José Callado-Muñoz \& Natalia Utrero-González}

To cite this article: Francisco José Callado-Muñoz \& Natalia Utrero-González (2019): Integration in the European higher education area: the case of military education, Defence Studies, DOI: 10.1080/14702436.2019.1681897

To link to this article: https://doi.org/10.1080/14702436.2019.1681897

曲 Published online: 28 Oct 2019.

Submit your article to this journal ¿

LII Article views: 18

Q View related articles $\square$

View Crossmark data $־$ 


\title{
Integration in the European higher education area: the case of military education
}

\author{
Francisco José Callado-Muñoz and Natalia Utrero-González
}

Centro Universitario de la Defensa Zaragoza, Academia General Militar, Zaragoza, Spain

\section{ABSTRACT}

Military training has always been considered as an education system with its own characteristics that distinguished it from the rest of higher education. However, different initiatives have been developed in order to integrate military education in the European Higher Education Area (EHEA). This paper analyses the European system of military institutions of higher education (MHEI). Results indicate MHEl sector has distinctive features that have increased the diversity of European HEls. Further, the emergence of the MHEI sector can have benefits for both the European defence and their educational attainment. From a defence point of view, it can help the development of a European strategic culture and increase cooperation between countries in defence and security. From the education area modernisation, it will improve defence and security related research and may enhance defence knowledge transfer. In this way, the MHEl sector will be positioned as key player in the development of the Common Security and Defence Policy and a European strategic culture.

\section{ARTICLE HISTORY}

Received 12 June 2019

Accepted 15 October 2019

\section{KEYWORDS}

European higher education area; higher education institutions; institutional characteristics; military universities

\section{Introduction}

The evolution of the international security landscape has had significant implications for military professionalism, multinational military relations and alliances (Williams 2008). This new scenario has led to the appearance of new security demands (Colom Piella 2016) as well as the increase in missions traditionally assigned to the armed forces such as peace support operations, helping on the occasion of natural disasters and fighting terrorism (Caforio 2007). Further, new operations are increasingly multilateral, so military interoperability between different national armed forces becomes crucial (Cross 2011). In addition, military officers and soldiers must be capable to interact not only with units of other armies but with native population and personnel of international organizations with different values, codes of ethics and behaviour (Hude 2010). As a consequence, both the traditional defence model and training must adapt to meet these challenges (Williams 2008).

In this sense, this new scenario seems to require a different military preparation to incorporate specific training and education into military education (Nuciari 2007).

CONTACT Francisco José Callado-Muñoz fcallado@unizar.es C Centro Universitario de la Defensa Zaragoza, Academia General Militar, Carretera de Huesca s/n, Zaragoza 50090, Spain; Natalia Utrero-González $\otimes$ n.utrero@unizar.es ๑) 2019 Informa UK Limited, trading as Taylor \& Francis Group 
Tactics and education on combat training remains necessary but it is no longer sufficient. Giving priority to academic education on politics, leadership and technical skills that complement human values is needed to provide the professional abilities officers currently need (Kirkels et al. 2003). At the same time, military training centres have experienced a remarkable expansion and transformation (Barrett 2009). In particular, they have evolve to become centres of intellectual activity that promote international cooperation in defence and security (Caforio 2007).

The education of officers in the European Union (EU) has not been alien to these circumstances. On the one hand, the military academies have made efforts to improve the preparation of future officers trying to respond to the defence challenges and increase cooperation at European level. These changes have materialized in the growing integration between the national military education and civilian education systems. Actually, European military education has taken advantage of the European Higher Education Area (EHEA) started with the declaration of Bologna in 1999 to renew itself and to improve its academic standards. In particular, this EHEA has provided a common standardized framework but flexible enough to adapt the military curriculum (Paile 2016) and has facilitated the process of external accreditation.

In a way, there has been a confluence of objectives between the adapting needs of military education and the Bologna process. The recognition and comparability of degrees in European higher education, the promotion and cooperation between entities, as well as the mobility of students, professors and researchers -objectives of the EHEA- have their correspondence in the main issues in the process of renewal of military education: European defence culture, alignment with civilian education or interoperability. As a consequence, a coherent military higher education system has been consolidated across Europe and the Military Higher Education Institution (MHEI) has emerged. Developing such institutions has also pursued to increase collaboration and exchanges between national Armies and education facilities as suggested in the EU Common Security and Defence Policy (CSDP) agenda. Despite the relevance of military education and the increasing presence of CSDP in the international scenario, European military university sector has not been previously analysed.

Therefore, this paper analyses the current state of the process of incorporation and integration of the MHEIs to the EHEA. In particular, it deals with the recent evolution of European defence universities and colleges between the years 2011-2015 with the aim of characterizing them and contrasting their similarities and differences with the rest of higher education institutions (HEIs). It will also assess the level of achievement of some of the key objectives of the EHEA. This is the main contribution of this work.

This paper is related to papers that analyse European military academies and military continuous education for military officers. On the Paile $(2010,2016)$ ) makes a comparison of the curricula of the military academies and the efforts to increase mobility; Callado-Muñoz and Utrero-González (2016) make a comparison of the European military academies and the advent of security and defence universities. On the latter, Libel (2016) analyses the case of advanced education in five European countries. This work differs from the previous ones in several aspects. First, it focuses on the European MHEI sector. To do so, information from national sources is completed with data from the European Tertiary Education Register (ETER). ETER data is homogeneous and allows comparisons between the military and civilian HEIs. Second, the period 
analysed permits us to show the changes produced in MHEIs. Finally, the differences between MHEI and the rest of the universities are analysed.

The structure of the paper is as follows. The second section describes briefly the European military education landscape and its relationship with the MHEI sector. The third explains the nature and origin of the data. The fourth presents the analysis of the MHEI sector and its comparison with European HEIs. Finally, the last section presents conclusions.

\section{European military higher education landscape}

Military education has a dual nature: vocational (to become a soldier to defend the national territory and preserve nation values) and academic (to be able to deal with the complex challenges they face in the future) (Kelley and Johnson-Freese 2013). Traditionally military education curricula have been a mixture of the two (Foot 2006). Recently, academic content has increased its relevance in military preparation as well as there has been an effort to augment its academic standards to gain institutional legitimacy and recognition as cultural elites and genuine holders of knowledge related to defence (Libel 2016). European military education has not been alien to this trend. In particular, all 28 European Union member countries assimilate their military education systems to higher education with a trend to increase in the future (Paile 2008). In addition, there have been many initiatives to integrate military educational institutions into the European Higher Education Area (EHEA). As the objective of the process was to reach harmonisation to improve international cooperation but not standardisation, the implementation of the new education model has been very different within the Member states (Paile 2016). ${ }^{1}$ Two main features defined the education system chosen. First, the institution responsible for the academic pillar of officer education. In some cases, the academisation process has given rise to military universities that imply the renewal of historic traditions and are accredited as full-fledged actors of the EHEA. In others, the academic pillar is entrusted to partner institutions associated with civilian universities or directly to civilian HEIs and therefore separated from the vocational training. Second, the establishment of service-based or joint education models. Accordingly, some European countries have more than one MHEI such as France, Poland or Romania, others have a joint MHEI such as Belgium or Finland. Some have settled in-house defence colleges in association to established HEIs while others directly delegate education to civilian universities. Netherlands and Spain are examples of the former, Italy of the latter ${ }^{2}$. Table 1 collects the national features.

Independently of these differences, the new model of military academic education implies a change in the faculty hired. In traditional military academies, the faculty

Table 1. European national military education system characteristics (EU-28).

\begin{tabular}{|c|c|c|c|}
\hline \multicolumn{2}{|c|}{ Defence University } & \multirow{2}{*}{$\begin{array}{l}\text { Association/ } \\
\text { Delegation Civilian } \\
\text { University }\end{array}$} & \multirow{2}{*}{$\begin{array}{l}\text { Without National } \\
\text { Military Education } \\
\text { System }\end{array}$} \\
\hline Joint MHEI & Service MHEI & & \\
\hline $\begin{array}{l}\text { Austria, Belgium, Czech Republic, Estonia, } \\
\text { Finland, Germany, Denmark, Hungary, } \\
\text { Netherlands, Slovakia, Sweden. }\end{array}$ & $\begin{array}{l}\text { Bulgaria, France, Greece, } \\
\text { Lithuania, Poland, } \\
\text { Portugal, Romania. }\end{array}$ & $\begin{array}{l}\text { Croatia, Ireland, } \\
\text { Italy, Latvia, } \\
\text { Slovenia, Spain, } \\
\text { UK. }\end{array}$ & $\begin{array}{l}\text { Cyprus, } \\
\text { Luxemburg, } \\
\text { Malta. }\end{array}$ \\
\hline
\end{tabular}


consisted of military officers. In contrast, the new education model is characterised by civilian-military, academic-professional faculty to promote curricular improvement and higher intellectual standards without weakening the professional military identity (Paile, 2011). Further, the most important change when the officer education becomes accredited is that the military share control and power over the military education with the university; and as part of the national university system, the military has to accept university laws and regulation (Hedlund 2013).

\section{Data}

In this paper, we analyse the new European MHEI sector and compare to its civilian counterparts. For that, we use the European register of tertiary education (ETER). This database collects information from those educational institutions that provide higher education degrees (undergraduate, masters and doctorate) and have been accredited as HEIs by the competent national authority. The ETER coverage includes EU-28 countries, as well as Albania, Iceland, Liechtenstein, Montenegro, Norway, Serbia, Switzerland, Turkey and the Republic of North Macedonia and corresponds to the period 2011-2015. The main advantage of ETER is that the data are collected individually and homogeneously for each of the institutions included, offering the possibility of evaluating their diversity according to their main characteristics. However, the ETER database has two features that condition the analysis of the MHEI sector. First, for some countries, relevant information is missing as the case of Romania and the French part of Belgium. Second, it only collects information on accredited institutions but not on their different faculties or colleges. This is a relevant issue for the countries with associated/delegated civilian universities such as Italy or Ireland or have developed colleges affiliated to existing HEIs such as Latvia and Spain.

Taking into account the national features of military education and ETER characteristics, we are able to identify 39 military institutions of higher education (MHEI) from 19 different countries, 16 of which belong to the European Union. ${ }^{3,4}$ This is $88 \%$ and $89 \%$ of the EU members' countries and defence universities respectively. In order to include defence colleges affiliated to civilian universities in the analysis, information on Spanish defence colleges has been collected.

Building on the work of Lepori et al. (2016) and case studies by Libel (2016) a set of parameters that define the activity develop by each institution and help to explain their distinct characteristics are going to be analysed. In particular, age, type of institution, legal status, and degrees offered, size, presence of women and mobility.

\section{Analysis of MHEI}

\section{History and demography of $\mathrm{MHEI}$}

To understand the origin and consolidation of MHEI sector, it is interesting to study the date of foundation, as well as the evolution of the number of institutions and students. Figure 1 collects this data. Some of the MHEI come from the transformation of the old military academies, as reflected by the fact that more than $34 \%$ have their foundation before the Second World War. 17\% of MHEIs, on the other hand, are founded in the last 


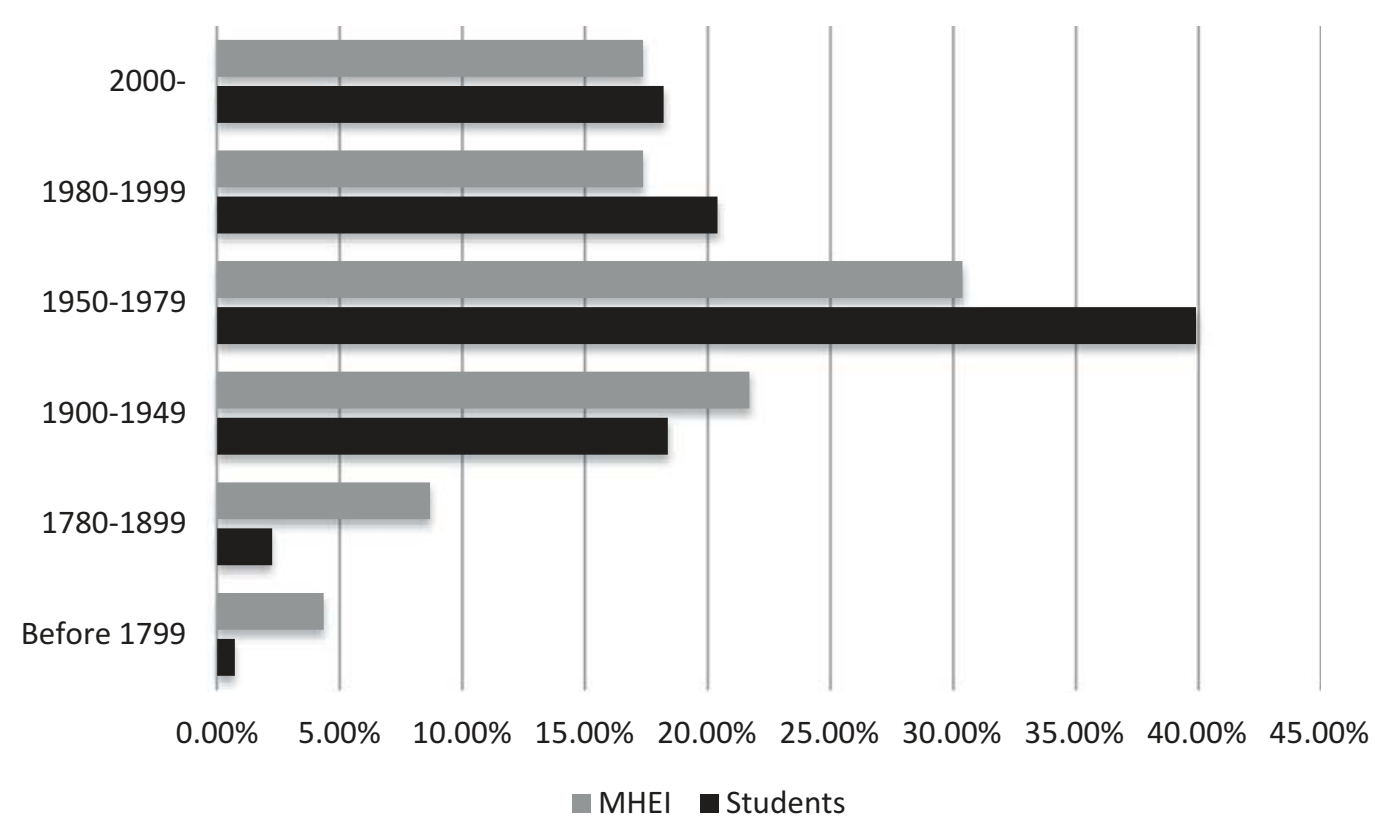

Figure 1. MHEls by foundation period. 2015.

years of the 20th century. This evolution is similar to that which occurred in general for HEIs (Lepori et al. 2016) and would reflect, on the one hand, the expansion of tertiary education in the second half of the 20th century and, on the other, national circumstances, such as the independence of the Baltic countries. Another factor widely studied in the case of HEIs is the disappearance and/or merger of institutions. However, this is not a relevant factor in the MHEI sector. During the period analysed there has been no disappearance of MHEI. The only merger case is the National Public Service University in Budapest, whose origin is the aggregation of the academies of defence, security, and public administration. Regarding the number of students, institutions founded in the period just after the Second world war concentrate $40 \%$ of the students (see Figure 1).

Analysing the different types of students and the age of the MHEI, it is observed that institutions founded in the second half of the $20^{\text {th }}$ century have a greater number of $\mathrm{PhD}$ students. Specifically, 54\% of the those MHEIs offer the possibility of pursuing doctoral studies and the number of doctoral students in them arrives at $68 \%$ of total students compared to the oldest MHEI with no doctorate (see Table 2). In addition, the youngest MHEI presents more than $25 \%$ of doctoral students. This fact suggests that young and middle age MHEIs have been born with a greater vocation for research and confirm the interest to increase the quality of the curricula of military training (Barrett 2009). This evidence contrasts with the analysis of European HEIs, where the oldest group concentrates the largest number

Table 2. Characteristics of MHEl students by foundation period. 2015.

\begin{tabular}{lccccc}
\hline & MHEI & Doctorate & Without Doctorate & Bachelor students & Doctorate students \\
\hline Before 1799 & 1 & 0 & 1 & 102 & - \\
$1800-1899$ & 8 & 0 & 2 & 316 & - \\
$1900-1949$ & 9 & 4 & 1 & 2535 & 55 \\
$1950-1979$ & 10 & 4 & 3 & 5334 & 294 \\
$1980-1999$ & 5 & 2 & 2 & 2571 & 306 \\
$2000-$ & 6 & 2 & 2 & 2339 & \\
Total MHEI & 39 & $52.17 \%$ & $47.83 \%$ & & \\
Total HEI & 2204 & $49.23 \%$ & $50.77 \%$ & & \\
\hline
\end{tabular}


of undergraduate and doctoral students (Lepori 2018a). Overall, the proportion of institutions that offer doctorates is not very different between the MHEIs and HEIs, although in the case of MHEIs the proportion is greater exceeding half of the institutions.

International comparisons of the tertiary education sector have defined two models of higher education systems. The unitary model, where all HEIs are governed by the same regulations, and the binary model (De Lourdes Machado et al. 2008). In the latter, there are two types of HEI, one more associated with academia and research (University) and another with a focus on more professional education (University of Applied Sciences), although these differences have reduced in some cases (Lepori and Kyvik 2010). Spain, Italy or Lithuania have unitary systems while Denmark, Holland, Finland or Norway are representatives of the binary system. Another aspect of interest with substantial differences among countries is the legal status: whether they are public or private property. In the case of the MHEIs, given the fundamental role of the armed forces for the national welfare and protection of society, it would be expected that the presence of private MHEIs would be minimal. Table 3 shows these characteristics.

More than $46 \%$ of the MHEIs analysed have university status. Therefore, they can grant doctorate degrees. Only $15.3 \%$ fall within the category of universities of applied sciences. Compared with the HEI sector, this percentage is much lower. The MHEIs of applied sciences belong to Austria, Denmark, Estonia, and Lithuania. The first three countries have this type of institution in their national system of higher education, but not Lithuania, where all their HEIs are classified as universities.

Regarding legal status, as would be expected, all institutions except two are publicly owned. The Academy of armed forces General Milan Rastislav of Slovakia is a private governmentdependent university, and therefore subject to greater public control than a private institution. Specifically, they receive more than $50 \%$ of their budget and the staff is covered by the state. This situation contrasts with the rest of HEIs in which more than $25 \%$ are private and the rest are divided between $60 \%$ public and $12.4 \%$ private concerted. However, if we look at the number of students enrolled for each type of institution, the results for MHEIs are not that far from HEIs: private entities only serve $8 \%$ of university students (2.55\% for MHEIs) and less than $2 \%$ (7.4\% for MHEIs) of those who study a university doctorate.

\section{Specialisation}

Another variable that usually characterizes the differences between European HEIs is the degree of specialisation of the academic offer. Usually, a HEI is considered as specialised

Table 3. Main characteristics of MHEls by foundation period. 2015.

\begin{tabular}{|c|c|c|c|c|c|c|}
\hline & \multirow[b]{2}{*}{ MHEI } & \multicolumn{3}{|c|}{ Category } & \multicolumn{2}{|c|}{ Legal Status } \\
\hline & & University & Applied Science & Other & Public & Private- Public \\
\hline Before 1799 & 1 & 0 & 1 & 0 & 1 & 0 \\
\hline $1800-1899$ & 8 & 1 & 0 & 7 & 8 & 0 \\
\hline 1900-1949 & 9 & 8 & 0 & 1 & 9 & 0 \\
\hline 1950-1979 & 10 & 6 & 0 & 4 & 9 & 1 \\
\hline 1980-1999 & 5 & 1 & 3 & 1 & 5 & 0 \\
\hline $2000-$ & 6 & 2 & 2 & 2 & 6 & 0 \\
\hline Total MHEI & 39 & $46.15 \%$ & $15.38 \%$ & $38.46 \%$ & $97.44 \%$ & $2.56 \%$ \\
\hline Total HEI & 2204 & $43.42 \%$ & $29.08 \%$ & $27.50 \%$ & $60.12 \%$ & $12.43 \%$ \\
\hline
\end{tabular}


when a single field of knowledge collects at least $80 \%$ of the students. The focused HEI tends to present a dominant field that includes more than half of the students. Finally, there would be the generalist HEI where there is not a single discipline in which more than half of the students are enrolled.

Table 4 shows the results for the degree of specialization by MHEI, by country and by year analysed. Being a new-born sector, it is interesting to analyse its evolution. As can be seen, more than half of the MHEI are focused in 2015, 31.5\% are specialized and only $6.89 \%$ are generalists. The two German MHEIs (the University of the Armed Forces in Hamburg Helmut-Schmidt and the University of the Armed Forces in Munich), as well as the National Defence College of the Swedish armed forces, are the generalists. The reduction of the degree of specialization throughout the period analysed corresponds with the expansion of the academic offer of the MHEIs. The objective was to incorporate training in different competences military officers will need in the accomplishment of their missions. Despite its decrease, the predominance of focused institutions and specialists in the MHEI sector contrasts with the equality in the distribution of the three types in HEIs, where the relevance of generalists has been reduced by the growth of focused and specialized institutions (Wagner-Schuster 2018).

Analysing the relationship between specialization and typology, it can be verified that the MHEIs classified as universities are the only ones with a presence in the generalist category. In contrast, the universities of applied sciences are distributed between focused or specialized; none of them is of a generalist type (see Figure 2). Again, this evidence is similar to that found by Wagner-Schuster (2018) for the total of HEIs.

Regarding the areas of specialization provided by the European MHEI, the services area (human resources, transport, and security) stands out with more than $30 \%$ of the undergraduate students, followed by engineering and thirdly business and law. This same classification is maintained for masters and doctoral students, although business and law and engineering exchange their position, accentuating the differences in the level of training (See Figure 3).

\section{Size}

To analyse MHEI size, we use the total number of students enrolled and the classification proposed by Daraio et al. (2011). Table 5 presents the data. Approximately, a quarter of the MHEIs are very small with less than 500 enrolled students. During the period of analysis, small and medium MHEI oscillate between 22\% and 47\%. Data for the year 2014 and 2015 show an increase in the percentage of medium MHEI to the detriment of small ones. In the sample analysed, there are no large MHEI (up to 20,000 students) or very large MHEI (more than 50,000 students).

This heterogeneity in the size of the MHEI is also observed in the case of HEIs, although with notable differences. The medium HEIs have the greatest weight in all European countries, while there is more heterogeneity for MHEIs (see Table 6). Previous literature relates the size of European HEIs with their age, the number of studies offered and the research activity (Lepori et al. 2016). In the case of MHEIs, these differences are associated not only with the size of the country and the armed forces but with the fact that in some countries the same institution provides education and training to all services as shown above in Table 1. 


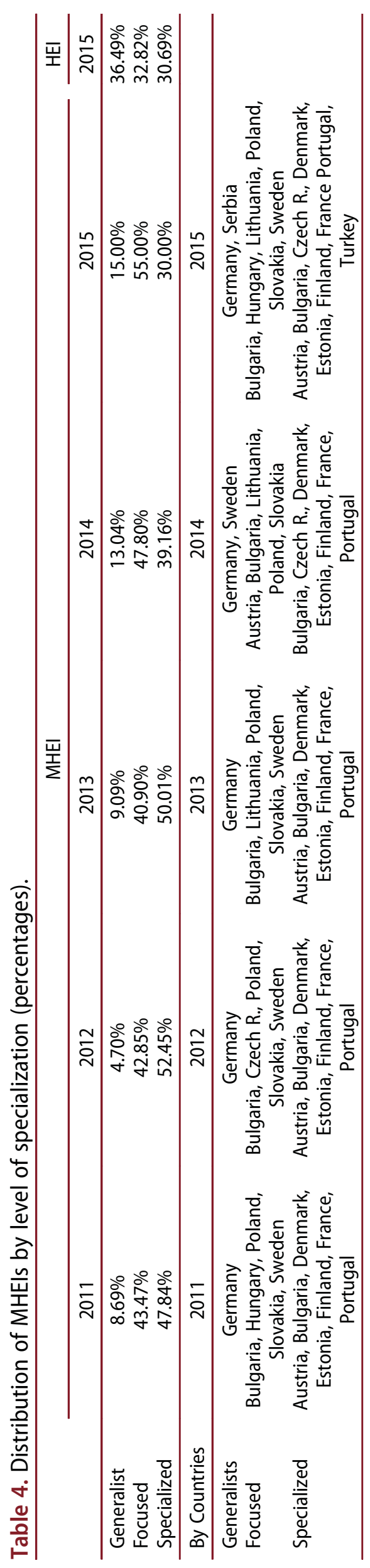




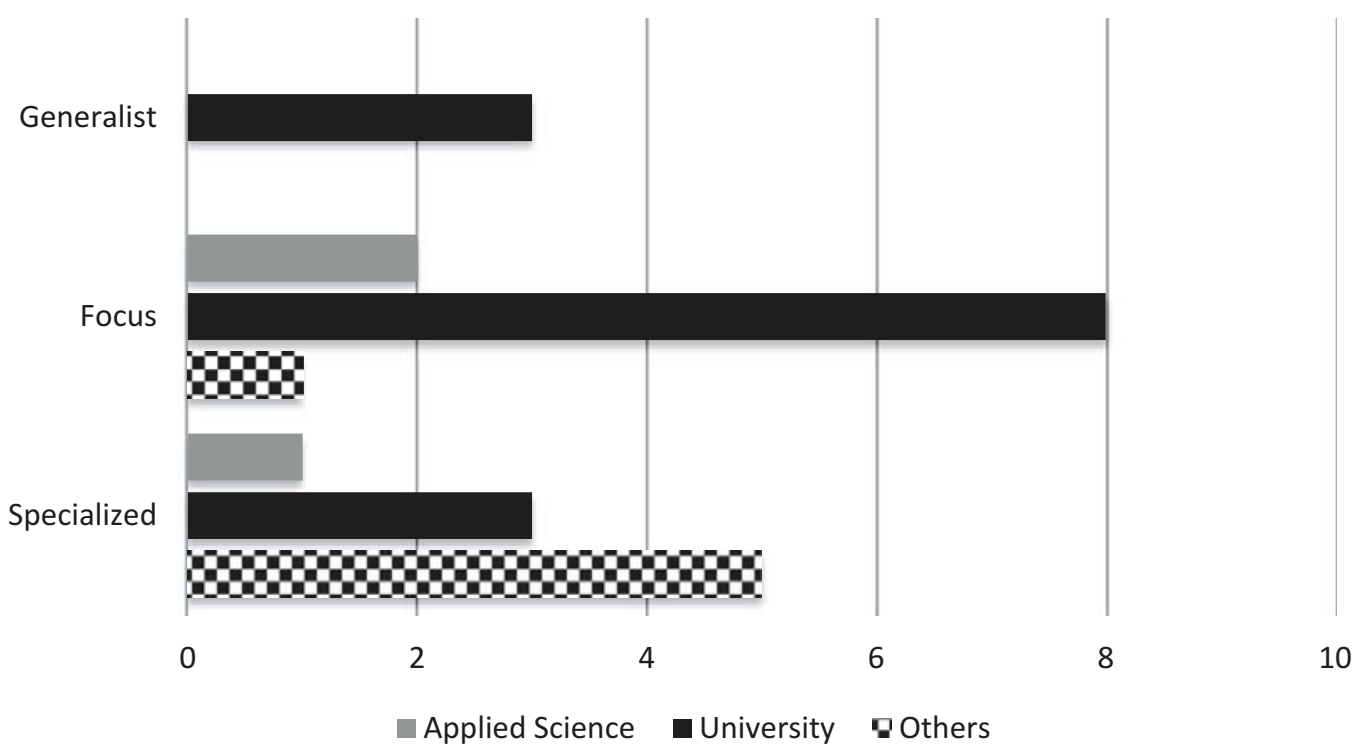

Figure 2. Relationship between typology and specialization. 2015.

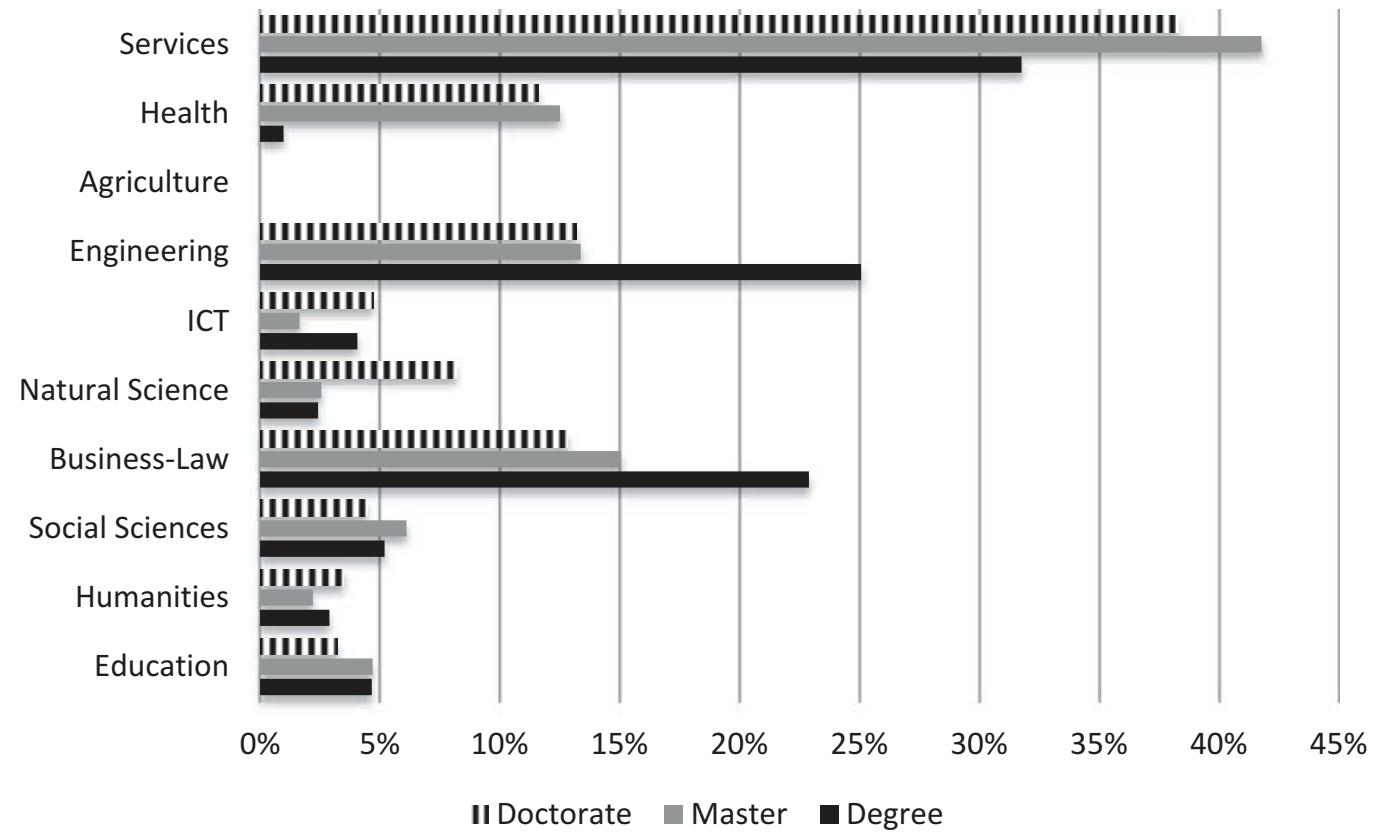

Figure 3. Distribution of the number of MHEl students by area of specialization. 2015.

Table 5. Distribution of MHEI/HEl by number of students (percentages).

\begin{tabular}{lrrrrrrr}
\hline & \multicolumn{3}{c}{ MHEI } & & HEI \\
\cline { 2 - 6 } & \multicolumn{1}{c}{2011} & 2012 & 2013 & 2014 & 2015 & 2015 \\
\hline Very small $(<500)$ & $38.46 \%$ & $38.46 \%$ & $34.38 \%$ & $37.04 \%$ & $26.09 \%$ & $18.00 \%$ \\
Small (500-2000) & $30.77 \%$ & $34.62 \%$ & $31.25 \%$ & $22.22 \%$ & $26.09 \%$ & $27.00 \%$ \\
Medium (2000-20000) & $30.77 \%$ & $26.92 \%$ & $34.38 \%$ & $40.74 \%$ & $47.83 \%$ & $43.00 \%$ \\
Large (20000-50000) & $0.00 \%$ & $0.00 \%$ & $0.00 \%$ & $0.00 \%$ & $0.00 \%$ & $10.00 \%$ \\
Very large (>50000) & $0.00 \%$ & $0.00 \%$ & $0.00 \%$ & $0.00 \%$ & $0.00 \%$ & $2.00 \%$ \\
\hline
\end{tabular}

To better understand these differences, size is analysed in relation to legal status, typology, academic offer and the specialization of the MHEI through box plots (see Figure 4). The public MHEI are larger than the private one with public control. 
Table 6. Distribution of MHEI countries by number of students.

\begin{tabular}{ll}
\hline & \multicolumn{1}{c}{$2011-2015$} \\
\hline Very small $(<500)$ & Austria, Estonia, Portugal, Slovakia \\
Small (500-2000) & Bulgaria, Czech R., Denmark, Finland, Lithuania, Sweden \\
Medium (2000-20000) & Germany, Hungary, Poland, Bulgaria (Vasil Levski Academy) Turkey (Military Academy) \\
\hline
\end{tabular}

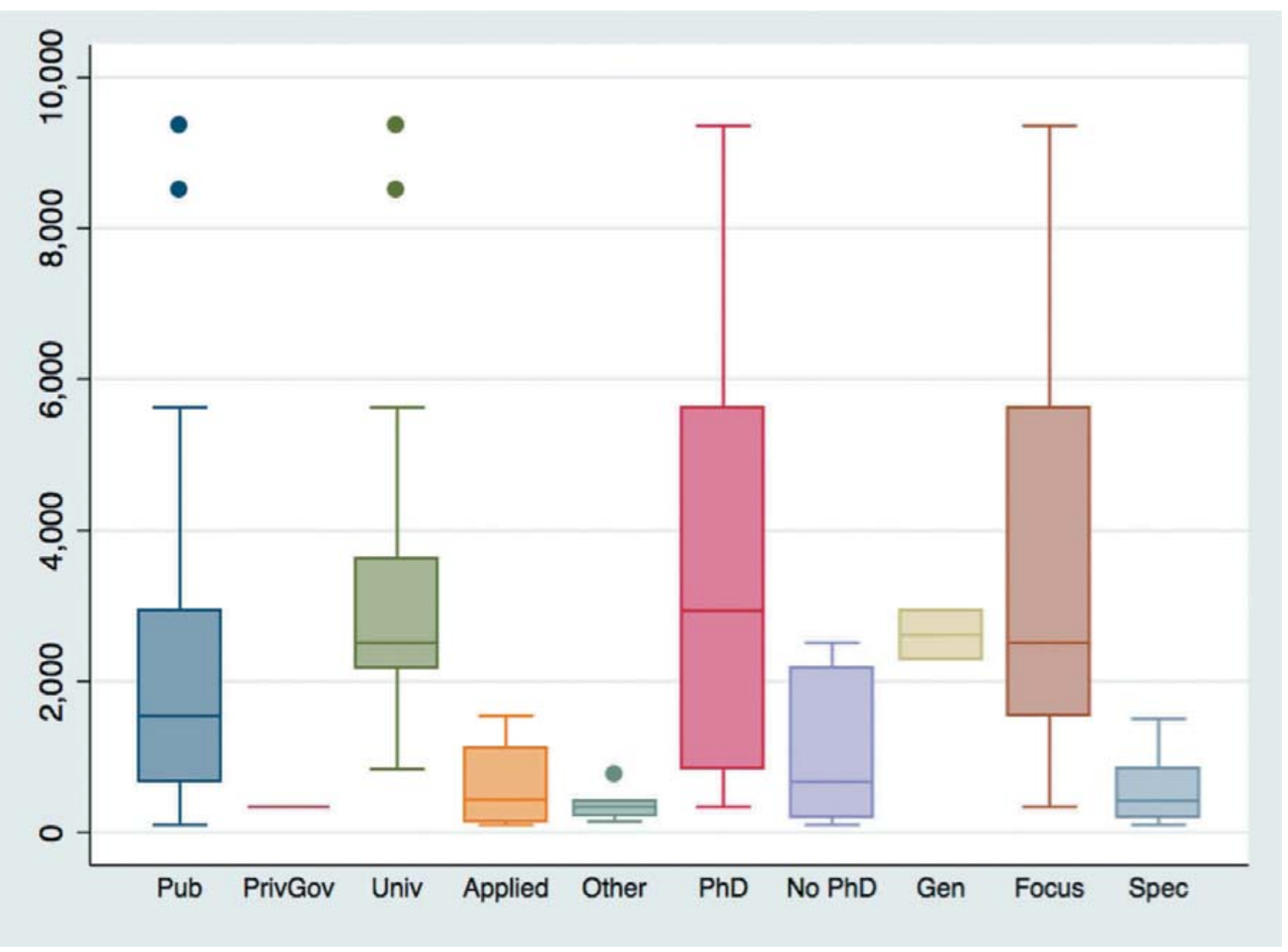

Figure 4. Distribution of the number of students in MHEl by category. 2015.

Regarding the type of MHEI, the universities are the largest, followed by the universities of applied sciences and the category of others. As might be expected, the MHEI offering doctorates are larger. Perhaps the most surprising result is that the focused MHEI have more students than the generalist ones, something that does not hold for HEIs.

Another interesting aspect is the different heterogeneity of each category, as can be seen from the size of the boxes. Thus, the focused MHEI, those that award doctorates and the universities are the groups that present greater variation compared to the rest that show less variability and therefore greater similarity among the countries analysed.

\section{Gender equality}

Gender non-discrimination in all areas of society is part of the equality and human rights policies developed by the European Commission. In the case of higher education, it is intended to increase the incorporation of women in all academic areas on equal terms to prevent the loss of talent and increase diversity in decision-making (European Commision 2010). The analysis of HEIs has shown that in terms of students, on average, there are no significant differences between men and women (European Commission 
2015). Women have also achieved significant participation (more than 40\%) in academic positions. However, the percentages are much lower for professors. In addition, there is a lot of variability between the areas of knowledge (Lepori et al. 2016).

The case of the MHEIs is particularly interesting since the participation of women in the armed forces has traditionally been scarce and its incorporation in many countries did not occur until the end of the 20th century (and they could not always access all the bodies). Table 7 shows the average percentage of female students for the year 2015. As can be seen, the percentages are lower than in the case of HEIs. The Hungarian case stands out in the interval (40-60\%) that the European Commision (2010) defines as balanced. This result could be associated to the fact that the Hungarian MHEI is the result of a merger of academies of different public services as explained previously.

The situation of the academic staff is similar. The analysis by MHEI reveals that the presence of women is reduced. In more than $85 \%$ of the MHEIs, less than $40 \%$ of the academic staff is female. In the case of professors, the percentage is significantly lower, $80 \%$ of the MHEIs have less than $20 \%$ of professors (see Figure 5). These percentages are lower than for all the HEIs, but they are not so different for traditionally masculinised areas such as engineering (European Commission 2015).

The analysis by country reveals that there are no relevant differences in the participation of women as teaching staff, with the exception of Lithuania and Serbia. This is not the case for the percentage of professors (see Table 8) where there is a lot of variability. Serbia has the highest percentage of professors. The second highest percentage is that of Germany. The German result is remarkable, especially considering that until 2001, women did not fully join the armed forces. In the case of HEIs, more than half of the HEIs have achieved gender balance among academic staff, whereas only a minority (13\%) of HEIs has achieved gender balance for female full professors, (Hovdhaugen and Gunnes 2018).

Table 7. Percentage of female students in 2015.

\begin{tabular}{lccc}
\hline & IMES number & Graduates & Master \\
\hline Austria & 1 & $4.20 \%$ & $6.56 \%$ \\
Bulgaria & 1 & $16.86 \%$ & $20.29 \%$ \\
Czech Republic & 1 & $38.95 \%$ & $28.05 \%$ \\
Germany & 2 & $13.50 \%$ & $14.50 \%$ \\
Denmark & 1 & $6.09 \%$ &. \\
Estonia & 1 & $4.07 \%$ & $0.00 \%$ \\
Finland & 1 & $2.48 \%$ & $3.65 \%$ \\
France & 4 & - & - \\
Greece & 1 & - & - \\
Hungary & 1 & $48.09 \%$ & $50.71 \%$ \\
Lithuania & 2 & $19.42 \%$ & - \\
Norway & 1 & - & - \\
Poland & 5 & $34.45 \%$ & $47.34 \%$ \\
Portugal & 3 & - & $17.72 \%$ \\
Romania & 4 & - & - \\
Serbia & 1 & $55.47 \%$ & $55.77 \%$ \\
Sweden & 1 & $35.81 \%$ & $20.30 \%$ \\
Slovakia & 1 & $17.16 \%$ & - \\
Turkey & 4 & - & $27 \%$ \\
& Average & $20 \%$ & $20.30 \%$ \\
& Median & $18.29 \%$ & $55.77 \%$ \\
\hline
\end{tabular}




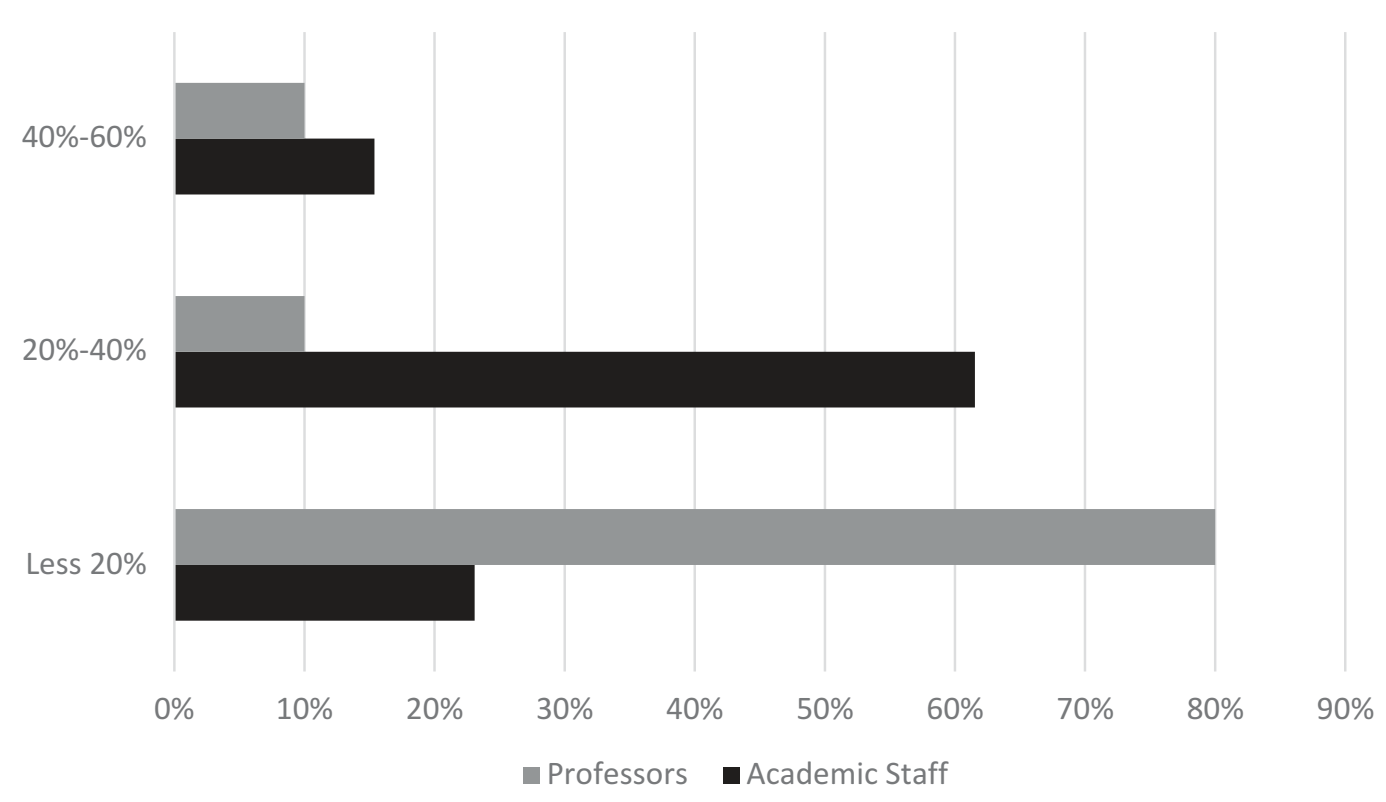

Figure 5. MHEl by percentage of women and category of teaching staff. 2015.

Table 8. Percentage of women in different academic positions 2014-2015.

\begin{tabular}{lcc} 
& Academic Staff & Professors \\
\hline Austria & $15.25 \%$ & $11.39 \%$ \\
Bulgaria & $27.74 \%$ & $7.44 \%$ \\
Germany & $27.97 \%$ & $18.11 \%$ \\
Hungary & $29.96 \%$ & $16.67 \%$ \\
Lithuania & $47.19 \%$ & - \\
Poland & - & $2.67 \%$ \\
Portugal & $17.00 \%$ & $12.75 \%$ \\
Serbia & $48.35 \%$ & $46.40 \%$ \\
Sweden & $26.32 \%$ & $4.25 \%$ \\
Slovakia & $26.32 \%$ & \\
Average & $29.89 \%$ & $14.96 \%$ \\
Median & $27.97 \%$ & $12.07 \%$ \\
\hline
\end{tabular}

\section{Mobility}

The national specificity of military education has not prevented exchanges. Traditionally, the academies, through bilateral agreements, have received foreign exchange students either for a specific period or to complete their training (for example Cypriot students in Greek academies). As can be seen in Table 9, these exchanges have little relevance.

One of the objectives of the Bologna process was to increase mobility due to its positive effects. The mobility of students improves the quality of education; in relation to teaching staff, it has become a fundamental part of the academic career (Enders and Musselin 2008) for its positive effects on research performance at the individual (CruzCastro and Sanz-Menéndez 2010) and institutional level (Horta 2009). Similarly, the renewal of officer training aimed at increasing international cooperation and collaboration. As members of the EHEA, MHEIs can participate in the Erasmus + program. The exchanges carried out within this program imply attending university courses in an institution different from the one of origin. However, the very specific nature of military 
Table 9. Mobility of students by country and Erasmus + exchanges in 2015.

\begin{tabular}{lccc}
\hline & Erasmus + incoming & Erasmus + outgoing & Foreign students \\
\hline Austria & $0.00 \%$ & $0.00 \%$ & - \\
Bulgaria & $0.25 \%$ & $8.16 \%$ & $4.66 \%$ \\
Czech Republic & $7.36 \%$ & $3.51 \%$ & $2.19 \%$ \\
Germany & - & - & $2.19 \%$ \\
Estonia & - & - & $0.00 \%$ \\
Finland & - & - & $0.00 \%$ \\
Hungary & $0.00 \%$ & $0.00 \%$ & - \\
Lithuania & $1.75 \%$ & $-14 \%$ & $0.71 \%$ \\
Norway & - & - & - \\
Poland & $0.92 \%$ & $1.80 \%$ & $0.24 \%$ \\
Portugal & - & - & $3.42 \%$ \\
Serbia & - & - & $0.37 \%$ \\
Sweden & $0.27 \%$ & - & - \\
Slovakia & - & & $0.00 \%$ \\
\hline
\end{tabular}

training has highlighted the need to develop tools that complement the mobility programs established by the EU. This is the origin of the initiative known as "Military Erasmus" (Paile 2016). Despite the interest of the EU, the common security and defence policy (CSDP) and the incentives of the European Security and Defence School (EESD), mobility during the period analysed has been scarce (see Table 9). In the case of HEIs, there has been an increase in mobility since the Bologna Declaration. While degree mobility at the bachelor level remains concentrated among a small number of HEIs, credit mobility fostered by the Erasmus program tends to focus on different countries (there are 12 universities with more than 1,000 incoming Erasmus students, seven of which are located in Spain) and educational levels (70\% of the Erasmus mobile students are at the bachelor level) and therefore plays a complementary role in extending the reach of international mobility (Lepori 2018b).

In addition to the little relevance of the exchanges, there are two remarkable aspects. The first is that the Erasmus + exchanges have been less important than the bilateral exchanges that were already taking place in the previous training system. This fact could be denoting some mistrust in the new education systems adopted in other countries and their validity for national defence beyond the traditionally accepted exchanges. In this sense, it could be expected that, as has happened with HEIs, the consolidation of MHEIs in the EHEA would mean an increase in exchanges. The second aspect to be highlighted is the variability among the countries where exchanges have taken place (both bilateral and Erasmus +). As explained above, mobility in HEIs is also more concentrated in some countries and in a small set of HEIs (Lepori 2018b). Therefore, mobility, and the elimination of obstacles, seems a pending issue in the integration process of the MHEIs in the EHEA. It would require a greater effort on the part of the institutions to advance in this idea of exchange and common learning community.

\section{Comparative analysis of the Spanish defence college with the European MHEI}

As we have seen, in seven EU countries civilian universities are commissioned to provide military academic tuition, and their information is not disaggregated in ETER. In order to complete the picture of the European MHEI sector, we have looked for information about the different counties. We were able to compile information about the Spanish 
system as an example of this kind of military training. The Spanish system was developed following the reform of the military career (law 39/2007) to provide a university official degree for future officers (RD 1723/2008).

Currently, there are four Defence Colleges (DC). In this section, their main characteristics are analysed and related to the evidence found for the MHEIs. The same parameters and classifications of previous analysis have been used. Table 10 contains the data corresponding to the year 2015.

All colleges are publicly owned. Their owner is the Ministry of Defence, but they are affiliated to civilian universities and therefore governed by the university academic regulations of the Ministry of Education. At this point, there is no difference with the MHEIs analysed.

The DCs are within the category of very small HEI, with the exception of the DC of Zaragoza that would be considered a small HEI. ${ }^{5}$ Therefore, by size, the DCs would be closer to the size of the MHEIs of Austria, Estonia, Portugal, Slovakia or Greece, smaller countries than Spain. However, it should be noted that Austria, Estonia and Slovakia have a joint DC while Portugal and Greece have differentiated service DC as it is the case in Spain.

Regarding the degree of specialization, a single degree is offered in each DC, and although some DCs have begun to develop master's degree programs in association with public universities, more than 80 percent of their students take the same degree. Therefore they are specialized HEIs. Accordingly, Spanish DCs differ from most of the MHEIs analysed in the degree of specialization, since the focused institutions in the case of the MHEIs exceed 50\%. However, except for the case of Finland, the majority of specialized MHEI correspond to countries with service MHEIs. Hence, differences come from the establishment of a joint or service educational institution rather than from differences in having a college or university accreditation.

Regarding the area of specialisation, the differences with the MHEIs analysed are more interesting. The main area of expertise in MHEIs is services (human resources, transport, and security), followed by engineering and economics and business. Engineering is the one chosen for Spanish DCs except for the Madrid DC whose area is health. One possible explanation is that some MHEIs have developed ad-hoc curricula with specific military content that have given rise to new academic degrees such as the degree in military science at the Swedish national defence school or a military leadership degree at the Teresian

Table 10. DC characteristics. 2015.

\begin{tabular}{lcccc}
\hline & Navy & Air & Army & Medicine \\
\hline Location & Marin & San Javier & Zaragoza & Madrid \\
Foundation Year & 2009 & 2009 & 2009 & 2012 \\
Army & Navy & Air & Land & Health Corps \\
Legal status & Public & Public & Public & Public \\
Students & 313 & 320 & 1005 & 68 \\
Specialization & Specialized & Specialized & Specialized & Specialized \\
Teachers & 35 & 28 & 104 & 111 \\
$\%$ Women Students & $3 \%$ & $3.75 \%$ & $8.70 \%$ & $58.14 \%$ \\
\% Women Teachers & $22.86 \%$ & $32.14 \%$ & $46.88 \%$ & $36.94 \%$ \\
Master & Yes & Yes & Yes & No \\
Doctorate & - & - & - & - \\
Mobility & Yes & Yes & Yes & - \\
Erasmus & Yes & Yes & - & - \\
\hline
\end{tabular}


military academy in Austria. Others have chosen to incorporate degrees with a high legal and management component such as German or Lithuanian universities. In contrast, the DCs opted, in their initial design, for existing civilian degrees in which a specific profile with greater presence of defence, leadership, management, and legislation in order to incorporate military specificity was introduced.

In relation to the presence of women, their percentage is significantly lower than the average for the MHEIs in the case of students. These results are striking because the incorporation of women into the Spanish armed forces occurred earlier than in other analysed countries. The exception is the Madrid DC, whose percentage of female students is above the average and closer to the results for the HEI population. This fact would be related to the area of specialization, health, with a traditionally high presence of women (Lepori et al. 2016). Army DC has the second highest percentage. This is related to the relevant number of female gendarmerie students in the first courses. However, if we look at the number of students in the last years of the degree, when there are no students from the gendarmerie, the percentage drops to levels similar to the Navy and the Air Force DCs. These low percentages are similar to those of HEIs for the engineering area and have led the EU to encourage female participation in these under-represented areas (European Commision 2014). Regarding the teaching staff, the percentage of women in all the DCs is higher than the average and the median of the MHEIs analysed with the exception of the Navy DC. The Army DC stands out with levels of balanced participation (more than 40\%), close to the figures of Lithuania's MHEI.

Finally, regarding the mobility of students, the DCs have inherited the tradition of the respective academies to send and receive students from different academies for a period of time, being the relationships with the academies of the United States and France the most important ones. The percentage of participating students is low as in the case of the MHEIs studied. Regarding participation in the Erasmus + program, taking advantage of the Bologna framework, all the DCs would have access to this possibility. The Air Force DC is the one that has already approved the letter Erasmus (2014-2020), although exchanges have not been realized yet within this programme.

Regarding the mobility of teachers, all the DCs have already made teacher exchanges (both received and sent) to other European MHEIs, although they have not been done through the Erasmus + program. Therefore, DCs would benefit, like the rest of the MHEIs, from measures to boost mobility. In this way, the initial advantages of the integration of military training in the EHEA would be reinforced, increasing international contact with future officers of allied countries and promoting the European strategic culture. It would also allow greater collaboration and confidence in the training of officers who will be allies in future missions.

\section{Discussion and conclusion}

This work makes a detailed study of the sector of the MHEI of 17 European countries and the Spanish DC system during the period 2011-2015. Results show the differences and similarities between the sector of MHEIs, the Spanish DCs and the rest of the HEIs of the EU.

The MHEIs have a series of distinguishing characteristics that differentiate them from the rest of the HEI. In particular, they are mainly public entities, offer undergraduate degrees and in some cases master's and doctoral degrees. On average they are smaller but 
with a greater degree of specialization. They are quite stable institutions. The Spanish DCs share with the MHEIs the public ownership and small size although they have a greater degree of specialization than the average MHEI. As specialised HEIs, MHEIs and Spanish DCs are providers of professional specific education, able to target both the future officer needs and develop their strategic priorities with high accuracy. But, as it happens with specialised HEIs, MHEIs and Spanish DC size may lead to issues of critical mass. Further, impact, research performance, and visibility seem to be easier to achieve for larger HEIs, which also tend to be at the top of research-based rankings (Lepori et al. 2017). In this sense, the emergence of joint MHEIs may be an interesting approach to preserve specificity and achieve a reasonable size.

Both in MHEIs and Spanish DCs mobility is reduced as it happens in the HEIs' sector. The amount of outward mobility in EU-28 countries' HEIs was a mere 2.9\% in 2013 (Lepori et al. 2018b) slightly higher than the 1.31 in their MHEIs analysed. Improving student mobility is one of the main objectives of both the European Higher Education Area and the Common Security and Defence Policy (CSDP). As for education policy, increasing mobility is a major priority for modernizing higher education. In this sense, the EU has established a target of $20 \%$ of graduates that study abroad (for an academic course) by 2020. As for the Common Security and Defence Policy (CSDP), the exchange of knowledge, skills and competences are keys for the preparedness of the European armed forces to work together and be able to interoperate and cooperate in the multinational military operations. For that, different proposals and training activities have been implemented to change this situation, not without difficulties, as evidenced by misgivings in the process of development of the "Military Erasmus" (Paile 2016). In this sense, the MHEIs could take advantage of the double interest (EHEA and CSDP) to improve mobility.

More than half of the HEIs included in ETER have achieved gender balance among academic staff, whereas only a minority (13\%) of HEIs achieved gender balance among female full professors (Lepori et al., 2018a). On the contrary, neither the presence of women is balanced yet nor the students or academic staff (in the MHEI or Spanish DC), as it happens in other traditionally masculinised areas of knowledge. Therefore, in the same way that the EU emphasises the need to promote gender equality to avoid talent loss, to diversify the views and approaches in research, and to foster excellence, it might be necessary to raise awareness to the presence of women in the defence and security sector to get closer to a balanced situation and introduce gender perspective in strategic defence and security.

Despite the differences evidenced and national idiosyncrasies, MHEIs and Spanish DCs have many points in common, with greater similarities than those that occur within the HEIs' sector and at the same time, they are pretty different from the rest of HEIs. This evidence can be interpreted both from the EHEA and the CSDP. The emergence of the military universities and Defence Colleges has enriched the HEI's population and has increased the diversity of Higher Education Institutions, which is considered as relevant issue for modernising higher education (Jongbloed and de Boer 2012). As a matter of fact, research is recognised, education is accredited and both aspects may influence positively knowledge transfer to society. From the CSDP, the advent of the sector is a positive factor for the development of a European strategic culture and the promotion of cooperation between European countries in defence and security. The differences found, however, show that work must be continued at different levels to deepen harmonization that would allow 
for greater cooperation and collaboration, as has happened in the European HEI sector since the approval of the Bologna plan. The MHEI have benefited from their initial integration in the EHEA, but evolution is necessary to promote progress and collaboration. Accordingly, the development of a strong European military epistemological community could not only be supported by institutions and veteran experts or officers, as suggested by Cross (2011) and Libel (2016) but could also be backed on common experiences during the educational period. In this way, the MHEI sector and its DC counterparts would be positioned as key players in the development of the CSDP and a European strategic culture.

\section{Notes}

1. Three countries do not have national military education systems and have agreements with other countries to send their nationals. Namely Cyprus, Luxemburg, and Malta.

2. See Callado-Muñoz and Utrero-González (2016) for a complete description of the relationship between military vocational and education training centres in the EU.

3. Austria, Bulgaria, Czech Republic, Denmark, Estonia, Finland, France, Germany, Greece, Hungary, Lithuania, Poland, Portugal, Romania, Slovakia, Sweden from the UE and Norway, Serbia, Turkey.

4. 33 institutions out of 39 are from the European Union.

5. It should be noted that the number of students of the Zaragoza DC includes those belonging to the corps of the Civil Guard who study the first two years in the CUD of the land army.

\section{Acknowledgments}

We are grateful to Benedetto Lepori for giving us the opportunity to visit Università della Svizzera italiana (USI) and the support with ETER database. Financial support from Ministerio de Educación y Ciencia through grants ECO2016-76255-P and ECO2017-86305-C4-2-R, Government of Aragón -Spain- and FEDER 2014-2020 Building Europe from Aragon" COMPETE (S52_17R) research group, University of Zaragoza (grant UZCUD2018-SOC-04) and the Defence University Centre Zaragoza grants 2017-21 and 2018-12;Centro Universitario de la Defensa Zaragoza [2017-21,2018-12].

\section{Disclosure statement}

No potential conflict of interest was reported by the authors.

\section{Funding}

Financial support from Ministerio de Educación y Ciencia through grants ECO2016-76255-P and ECO2017-86305-C4-2-R, Government of Aragón -Spain- and FEDER 2014-2020 "Building Europe from Aragon" COMPETE (S52_17R) research group, University of Zaragoza (grant UZCUD2018-SOC-04) and the Defence University Centre Zaragoza grants 2017-21 and 2018-12; Centro Universitario de la Defensa Zaragoza [2017-21,2018-12].

\section{Notes on contributors}

Francisco José Callado-Muñoz Associate Professor at Centro Universitario de la Defensa Zaragoza. PhD in Economics at Universidad Carlos III de Madrid, Spain. Author and co-author 
of more than 20 scientific articles and 10 book chapters. Reserch interests: Defence, Education economics, Financial economics, Payment Systems, Development, Business Economics.

Natalia Utrero-González Associate Professor at Centro Universitario de la Defensa Zaragoza. PhD in Economics at Universidad Carlos III de Madrid, Spain. Author and co-author of more than 20 scientific articles and 14 book chapters. Research interests: Defence, Education economics, Financial economics, Payment Systems, Development, Business Economics.

\section{References}

Barrett, J., 2009. Modern developments in defence education. Connections, 8 (2), 1-5. doi:10.11610/Connections.08.2.01

Caforio, G., 2007. Officers' professional preparation and issues posed by new military missions. International Review of Sociology, 17 (1), 87-104. doi:10.1080/03906700601129657

Callado-Muñoz, F.J. and Utrero-González, N., 2016. Educación superior en defensa y seguridad: una perspectiva europea. In: J.S. Serrano, P. Sánchez-Andrada, and I.Á. Rodríguez, eds. Libro actas DESEi+d 2016, 1339-1349. San Javier. Murcia, SpainMinisterio de Defensa.

Colom Piella, G., 2016. Transforming the Spanish military. Defence Studies, 16 (1), 1-19. doi:10.1080/14702436.2016.1146078

Cross, M., 2011. Security integration in Europe. Ann Arbor: University of Michigan Press.

Cruz-Castro, L. and Sanz-Menéndez, L., 2010. Mobility versus job stability: assessing tenure and productivity outcomes. Research Policy, 39, 27-38. doi:10.1016/j.respol.2009.11.008

Daraio, C., et al., 2011. The European university landscape: a micro characterization based on evidence from the Aquameth project. Research Policy, 40 (1), 148-164. doi:10.1016/j. respol.2010.10.009

De Lourdes Machado, M., et al., 2008. Reframing the non-university sector in Europe: convergence or diversity? In: J. Taylor, et al., eds. non-university higher education in Europe. Dordrecht: Springer, 243-259.

Enders, J. and Musselin, C., 2008. Back to the Future? the Academic Professions in the 21st Century. OECD, ed. Higher education to 2030 - volume 1: demography. Paris: OECD, 125-150.

European Commision, 2010. Stocktaking 10 years of "Women in science" policy by the European commission 1999-2009. Studies and Reports. Luxembourg: Publications Office of the European Union.

European Commision, 2014. Horizonte 2020. Promoting equality in science and innovation. Available from: http://ec.europa.eu/programmes/horizon2020/en/h2020-section/promotinggender-equality-research-and-innovation

European Commission, 2015. SHE figures 2015. European Commission. Luxembourg: Publications Office of the European Union.

Foot, O., 2006. Military education and the transformation of Canadian armed forces. Canadian Military Journal, Spring, 13-20.

Hedlund, E., 2013. Civil-military control over the Swedish military profession: an analysis from the perspective of officer rank and officer education. Armed Forces and Society, 39 (1), 135-157. doi: $10.1177 / 0095327 X 11426256$

Horta, H., 2009. Global and national prominent universities: internationalization, competitiveness and the role of the state. Higher Education, 58 (3), 387-405. doi:10.1007/s10734-009-9201-5

Hovdhaugen, E. and Gunnes, H., 2018. What ETER tells us about gender balance among academic staff in European HEIs. ETER brief $n$. 6 . The gender balance among academic staff. Available from: https://eter-project.com/uploads/assets/pdf/ETER_gender.pdf

Hude, H., 2010. A few reflections on the second meeting ISODOMA on military ethics and education. Who needs what, where and when? Colloquium, Joint Services and Command Staff College, Shrivenham, UK. 
Jongbloed, B. and de Boer, H., 2012. Higher education funding reforms in Europe and the 2006 modernisation agenda. The modernisation of European universities: Cross national academic perspectives, 1, 127.

Kelley, K.P. and Johnson-Freese, J., 2013. Getting to the goal in professional military education. Winter 2014. Orbis, 58(1), 119-131.

Kirkels, H., Klinkert, W., and Moelker, R., (eds.), 2003. Officer education: the road to Athens!. NL Arms, Netherlands Annual Review of Military studies.

Lepori, B., et al., 2016. Establishing a European tertiary education register (Contract EAC 2013-0308). Luxembourg: Publications Office of the European Union, Final Report.

Lepori, B., et al., 2017. Implementing and disseminating the European tertiary education register (Contract EAC 2015-0280). Luxembourg: Publications Office of the European Union, Final Report.

Lepori, B., 2018a. What ETER tells us about the history and demography of european heis. ETER brief n. 2. History and demography of HEIs. Available from: https://eter-project.com/uploads/ assets/pdf/ETER_brief_demography.pdf

Lepori, B., 2018b. What ETER tells us about student mobility in european higher education. ETER brief n. 3. Student mobility. Available from: https://eter-project.com/uploads/assets/pdf/ETER_ student_mobility.pdf

Lepori, B. and Kyvik, S., 2010. The research mission of universities of applied science and the future configuration of higher education systems in Europe. Higher Education Policy, 23, 295-316. doi:10.1057/hep.2010.11

Libel, T., 2016. European military culture and security governance. Oxon: Routledge.

Nuciari, N., 2007. Coping with diversity: military and civilian actors in MOOTW. International Review of Sociology: Revue Internationale de Sociologie, 17 (1), 25-53. doi:10.1080/ 03906700601129541

Paile, S., 2008. Towards a European culture of defence in officers' education: the initiative for the exchange of young officers inspired from Erasmus.In: Peace Research Institute Franckfurt (PRIF) Conference 2008, Vilnius, 11-12 December 2008.

Paile, S., 2010. The European military higher education. Stocktaking report. ESDC. Luxembourg: Publications Office of the European Union.

Paile, S. 2011. Europe for the Future Officers, Officers for the Future Europe, Compendium of the European Military Officers Basic Education. Ed. PolishMinistry of NationalDefense. Poland.

Paile, S., 2016. From European mobility to military interoperability. exchanging young officers, knowledge and know-how. ESDC. Luxembourg: Publications Office of the European Union.

$\mathrm{RD}, 1723 / 2008$ Creación sistema de centros universitarios de la defensa BOE-A-2008-18496. Available from: https://www.boe.es/buscar/doc.php?id=BOE-A-2008-18496

Wagner-Schuster, D., 2018. What ETER tells us about subject specialisation in European higher education. ETER brief n. 1. Subject specialisation in European higher education. Available from: https://eter-project.com/uploads/assets/pdf/ETER_brief_subjectmix.pdf

Williams, J.A., 2008. The military and society beyond the postmodern era. Orbis, 52 (2), 199-216. doi:10.1016/j.orbis.2008.01.003 